\title{
Análise de chuvas orográficas no centro do estado do Rio Grande do Sul
}

\author{
Analysis of orographic rainfall in the center of the state of Rio Grande do Sul \\ Francisco Rossarolla Forgiarini ${ }^{1}$, Daniel Secretti Vendrusculo ${ }^{2}$, Elias Silveira Rizzi ${ }^{3}$ \\ 1,2,3 Universidade Federal de Santa Maria, Santa Maria, Brasil
}

\begin{abstract}
Resumo
No Estado do Rio Grande do Sul (RS,) o regime pluviométrico não é homogêneo, apresentando variabilidade espacial e temporal condicionadas às interações de diferentes mecanismos climáticos. Estas particularidades fazem surgir diferentes comportamentos da chuva, incluindo as chuvas orográficas. O objetivo deste artigo é analisar a provável existência do efeito orográfico nas chuvas da região central do RS. O estudo foi realizado no município de Silveira Martins, situado no limite da Depressão Central e o Planalto Meridional Riograndense. Para atingir o objetivo, foi realizado o monitoramento das chuvas com a instalação de dez postos pluviométricos. Foram instalados quatro postos a barlavento e seis a sotavento de Silveira Martins, sendo comparados estatisticamente os totais médios precipitados nas duas posições. Além disso, caracterizaram-se os eventos de chuva, a partir de imagens de satélite do banco de dados digital do Instituto Nacional de Pesquisas Espaciais. O monitoramento totalizou 30 eventos de chuva e, ao nível de significância de 5\%, a análise estatística sugere a ocorrência de efeito orográfico. A partir da análise das imagens de satélite, pode-se evidenciar que o efeito orográfico da região intensifica as chuvas frontais decorrentes do movimento das massas de ar polares.
\end{abstract}

.Palavras-chave: Chuva de relevo, Análise estatística, Imagens de satélite.

\begin{abstract}
In the state of Rio Grande do Sul (RS) the rainfall is not homogeneous, showing spatial and temporal variability conditioned by interactions of different climatic mechanisms. Those features give rise to different behaviors of rainfall, including orographic rainfall. The aim of this paper is to analyze the probable existence of the orographic effect on rainfall in the central region of the RS. The study was conducted at Silveira Martins, situate on the edge of the Central Depression and Southern Plateau Riograndense. To achieve the goal was performed the rainfall monitoring with the installation of ten rain gauge stations. Stations were installed six upwind and four downwind of Silveira Martins, and statistically compared the average total at each position. In addition, we have characterized the events from satellite images of the digital database of the National Institute for Space Research. The monitoring totalized 30 events and, at the significance level of $5 \%$, the statistical analysis suggests the occurrence of orographic effect. From the analysis of satellite images can be evidenced that the orographic effect of the region intensifies frontal rainfalls due to movements of the masses of polar air.
\end{abstract}

Keywords: Orographic rainfall, Statistical analysis, Satellite images. 


\section{Introdução}

O estudo da variabilidade temporal e espacial das chuvas é base para diversos projetos e aproveitamentos da água pelo homem, tais como a construção de reservatórios, pontes e sistemas de drenagem, para a irrigação de culturas agrícolas e para o abastecimento doméstico (TUCCI, 2001). A chuva é formada por um conjunto de mecanismos, que possuem componentes locais e globais. Mendonça e Danni-Oliveira (2007) discutem que diversos fatores condicionam a sua ocorrência. Dentre os principais, destacam-se as características geográficas diversificadoras da paisagem, como latitude, altitude, relevo, vegetação e atividades humanas.

Neste contexto, o conhecimento de onde e como ocorrem as chuvas assume grande importância. Reichardt et al. (1995) afirmam que as chuvas podem ter grande variabilidade em pequenas distâncias. Segundo Bruno (2006), para obter informações precisas sobre a quantidade de chuva em uma área relativamente pequena, é necessário a instalação de uma estação pluviométrica a cada $3 \mathrm{~km}$ de distância, o que acaba sendo de elevada importância em estudos de inundações de pequenas bacias.

No Estado do Rio Grande do Sul, o regime pluviométrico não é homogêneo, apresentando variabilidade espacial e temporal condicionadas às interações de diferentes mecanismos climáticos (KHAN e KIM, 1998). Por um lado, o clima do Estado é controlado pelo avanço das massas de ar polares (direção principal sudoeste-nordeste), ao mesmo tempo, acontece a invasão de massas de ar subtropicais, até mesmo equatoriais, oriundas do canal de umidade da Amazônia (direção principal noroeste-sudeste). Outro fator que é responsável pela não homogeneidade das chuvas no Estado é o relevo (KHAN e KIM, 1998).

No centro do Estado está a Depressão Central, que é formada de rochas sedimentares, dando origem a um extenso corredor que liga o oeste ao leste, através de terrenos de baixa altitude. Do centro ao norte do Estado, situa-se o Planalto Meridional Riograndense, com terrenos de maior altitude, formado por rochas basálticas decorrentes de um grande derrame de lavas, ocorrido na era Mesozóica (SCP/DEPLAN, 2004).

Essas particularidades fazem surgir diferentes comportamentos da chuva no Estado, com a possibilidade de ocorrer as chuvas orográficas (ou chuvas de relevo). As chuvas orográficas ocorrem devido à influência do relevo, sendo que o ar que vai em direção à montanha (portanto na vertente de barlavento da mesma) é forçado a subir e condensa-se, devido à redução adiabática da temperatura, podendo causar chuva de maior intensidade e volume na área de aumento de altitude (SELUCHI et al., 2011). Após passar as montanhas, já desprovido de umidade, o ar desce e aquece adiabaticamente (LIEBMANN et al., 2011). Portanto, podem existir florestas ou poças a barlavento e áreas mais áridas, até charcos ou desertos, na vertente de sotavento (TUCCI, 2001).

Sendo assim, a região central do Estado e, especificamente, o município de Silveira Martins, apresenta condições favoráveis ao estudo das chuvas orográficas. Sendo vizinho ao município de Santa Maria, aquele município está no limite da Depressão Central e o Planalto Meridional, apresentando uma variação de altitude superior a 400 metros, em comparação à Santa Maria. Associado a isto, destaca-se o movimento das massas de ar que vão de encontro a essa barreira natural, tendo as condições para o aporte de umidade que provocariam as chuvas orográficas. No contexto discutido, o objetivo deste trabalho é avaliar a provável existência de efeito orográfico nas chuvas ocorridas no centro do Estado do Rio Grande do Sul, utilizando como estudo de caso o município de Silveira Martins.

\section{Material e Métodos}

A área de estudo localiza-se na região central do Rio Grande do Sul, no município de Silveira Martins $\left(29^{\circ} 38^{\prime} 35,85^{\prime \prime}\right.$ S; $\left.53^{\circ} 35^{\prime} 35,72^{\prime \prime} \mathrm{O}\right)$, distante $300 \mathrm{~km}$ da ca-

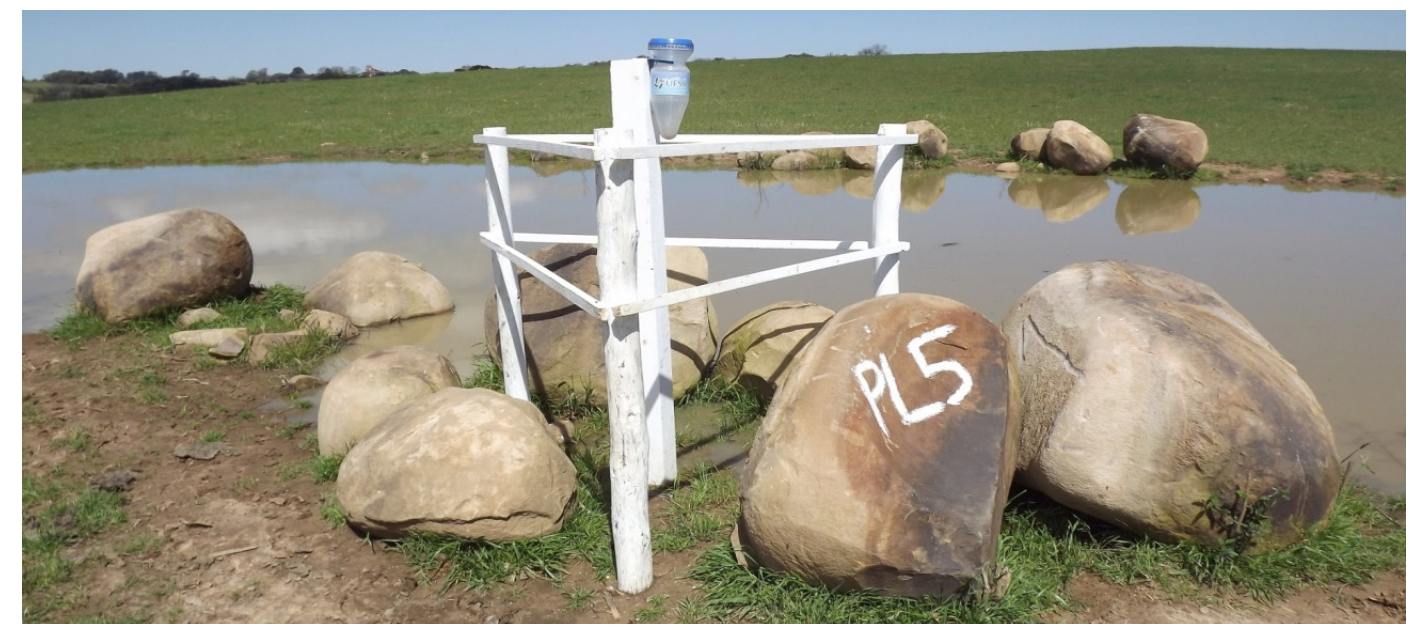

Figura 1. Posto pluviométrico número 5 (PL5). 

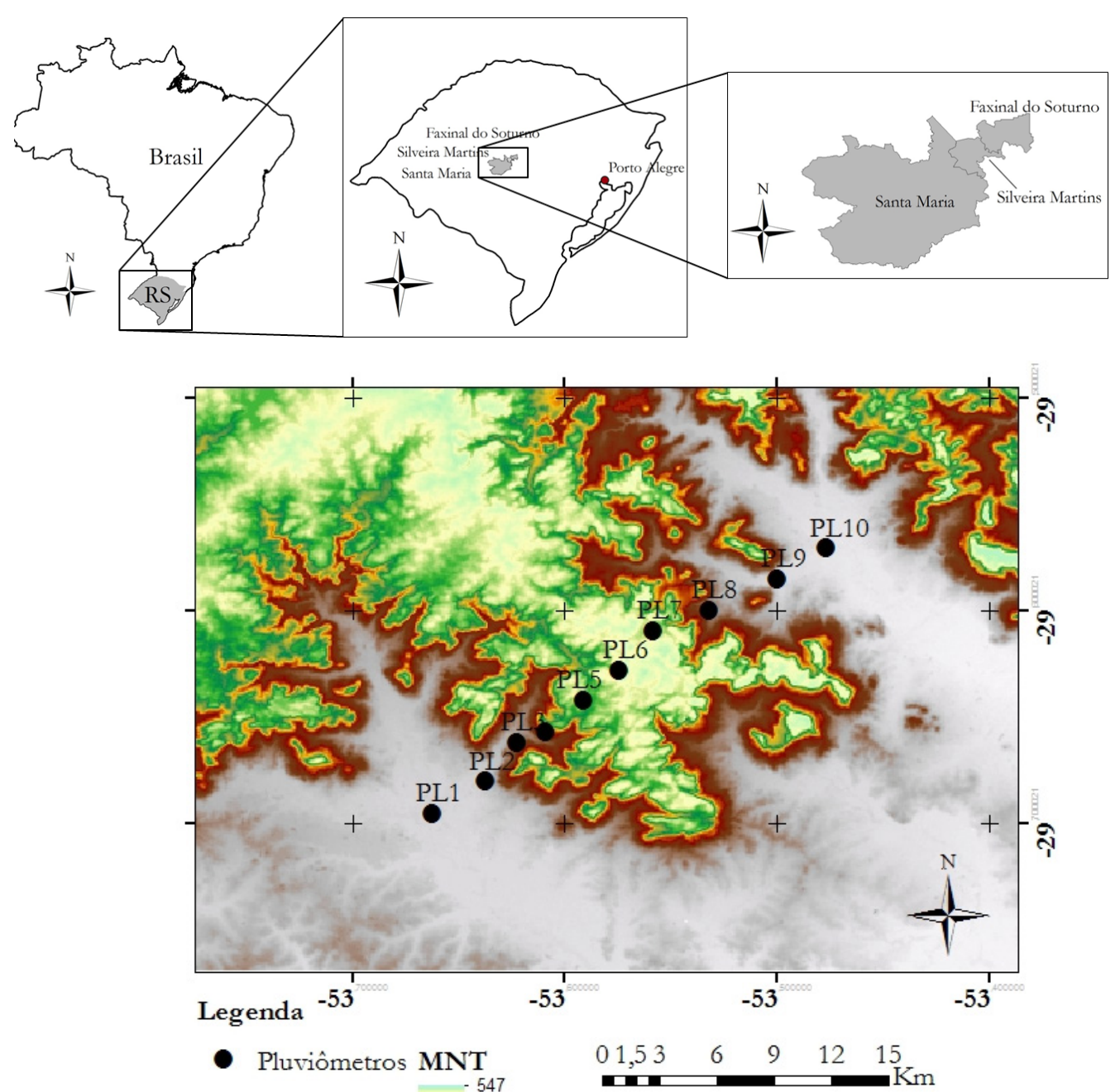

32 Coordenadas Geográficas - Datum: WGS 1984

Figura 2. Localização da área de estudo e dos pluviômetros a barlavento (PL1 a PL4) e a sotavento (PL5 a PL10).

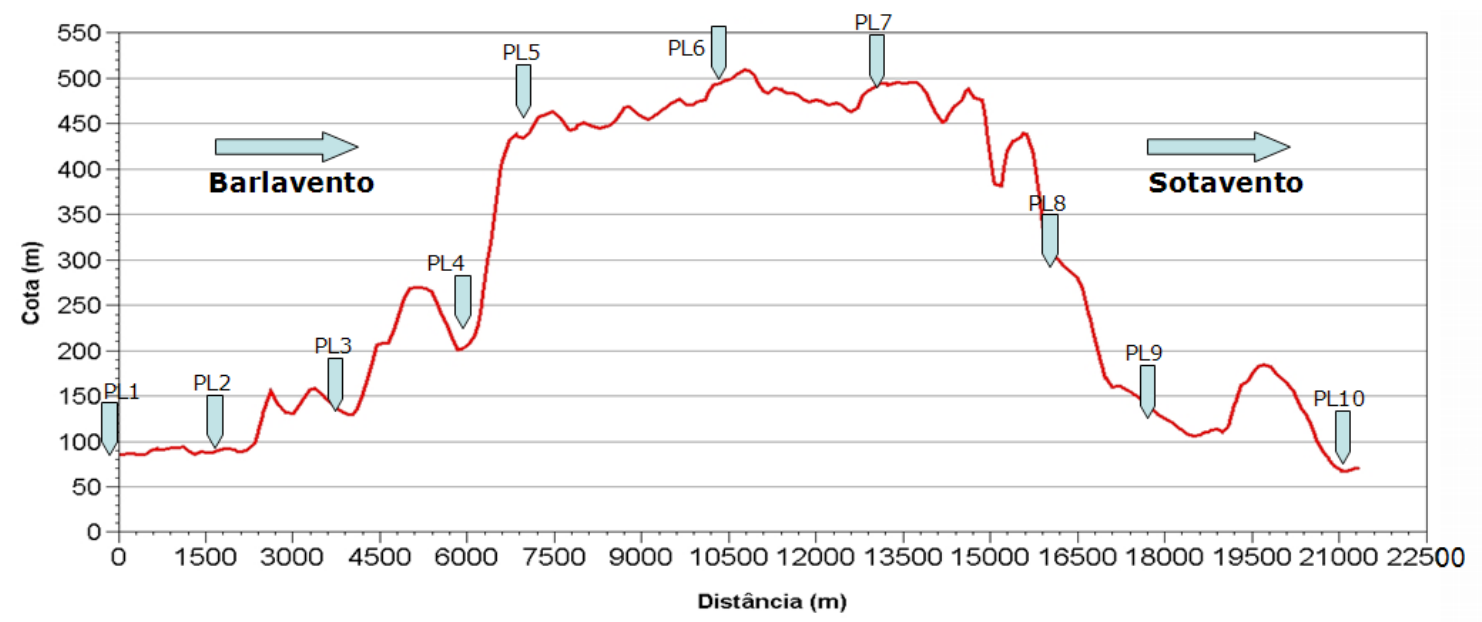

Figura 3. Perfil de elevação da região monitorada e localização dos pluviômetros. 
pital do Estado, Porto Alegre. Sua população é de 2.449 habitantes e sua área é de 118,42 km² (IBGE, 2011). Segundo a classificação de KÖPPEN, enquadra-se na área de clima temperado chuvoso e quente.

Foi realizado o monitoramento das chuvas a barlavento e a sotavento de Silveira Martins. Foram instalados pluviômetros (Figura 1) compostos por suporte de madeira, cerca de proteção e pluviômetro com anel de $101 \mathrm{~mm}^{2}$ e capacidade de armazenamento de $200 \mathrm{~mm}$.

O relevo da região caracteriza-se por uma elevação no sentido de Santa Maria a Silveira Martins (barlavento) e um decréscimo de altitude no sentido de Silveira Martins a Faxinal do Soturno (sotavento). A altitude em Santa Maria é de cerca de 80 metros acima do nível do mar, em Silveira Martins chega até 500 metros e em Faxinal do Soturno retorna a 80 metros. O monitoramento compreendeu a instalação de dez postos pluviométricos entre Santa Maria e Faxinal do Soturno, passando por Silveira Martins (Figura 2 e 3), ao longo de 21,5 quilômetros. Foram quatro ${ }^{1}$ pluviômetros a barlavento (PL1 a PL4) e seis pluviômetros a sotavento (PL5 a PL10), monitorados no ano hidrológico 2011-2012, de maio de 2011 a abril de $2012^{2}$.

Após cada evento de chuva, que abrangeu do início ao final da chuva, foram adquiridos os dados de cada pluviômetro e formado um banco de dados. A coleta ocorria em um mesmo dia, iniciando pelo PL1 e finalizando no PL10. Foram elaborados gráficos da relação entre altitude e chuva, observada nas duas posições, com objetivo de estimar uma taxa de aumento e redução da pluviosidade, ou seja, os gradientes pluviométricos a barlavento e a sotavento, conforme descreve Milanesi e Galvani (2011).

Além disso, foi realizado um teste de hipóteses unilateral para os totais médios observados nas duas posições. Foi utilizado o teste para a diferença de médias para pequenas amostras, de acordo com Spiegel et al. (2004). No teste, é analisado se as amostras vêm da mesma população, neste caso, se as chuvas são provocadas pelo mesmo processo, não existindo efeito orográfico. As comparações são as seguintes:

- D0: $\bar{X}_{1}=\bar{X}_{2}$, ou seja, não há diferença estatística significativa entre os totais de chuva observados a barlavento e a sotavento, o que sugere não haver efeito orográfico;

- D1: $\bar{X}_{1}>\bar{X}_{2}$, isto é, os totais de chuva a barlavento são superiores aos totais de chuva a sotavento, ou seja, há diferença estatística significativa, o que sugere haver efeito orográfico.

\footnotetext{
1 O planejamento inicial compreendia a instalação de 5 pluviômetros a barlavento (PL1 a PL5) e 5 a sotavento (PL6 a PL10). Porém, após a instalação dos pluviômetros e o início do monitoramento, constatou-se que o PL5 se localizava a sotavento.

2 No mês de junho de 2011 não ocorreu o monitoramento devido a problemas operacionais.
}

A estatística do teste é dada pelas equações abaixo (SPIEGEL et al., 2004):

$$
\begin{array}{cc}
T_{c}=\frac{\bar{X}_{1}-\bar{X}_{2}}{\sigma \sqrt{\frac{1}{n_{1}}+\frac{1}{n_{2}}}} & \text { Equação 1 } \\
\text { Sendo: } \sigma=\sqrt{\frac{n_{1} S_{1}^{2}+n_{2} S_{2}^{2}}{n_{1}+n_{2}-2}} & \text { Equação 2 }
\end{array}
$$

A distribuição de Tc é a distribuição $t$ de Student com $\mathrm{v}=\mathrm{n} 1+\mathrm{n} 2-2$ graus de liberdade. Sendo ni, Xi e $\mathrm{Si}$, respectivamente, os tamanhos, as médias e os desvios padrões das duas amostras. Será admitido o nível de significância de 0,05. Além do teste estatístico, foi estudado o movimento das massas de ar nos dias dos eventos de chuva, a partir de imagens do Satélite Ambiental Operacional Geoestacionário (GOES) disponíveis no Banco de Imagens do Instituto Nacional de Pesquisas Espaciais (INPE).

\section{Resultados e Discussões}

Durante o período de coleta, ocorreram 30 eventos de chuva (Figura 4), gerando um total médio, observado em todos os pluviômetros, de $953,13 \mathrm{~mm}$. O monitoramento indica uma pluviosidade $9,46 \%$ maior a barlavento do que a sotavento (Figura 5). Milanesi e Galvani (2011), que estudaram o efeito orográfico na Ilha de São Sebastião (mais conhecida como Ilha Bela, Estado de São Paulo), encontraram um percentual de $20 \%$ superior a barlavento do que a sotavento.

As Figuras 6 e 7 apresentam a correlação entre os totais precipitados e a altitude em cada posto pluviométrico, de acordo com a vertente (barlavento e sotavento). As análises das retas de regressão descrevem elevadas correlações em ambas as vertentes entre a chuva e a altitude. No barlavento a correlação foi de 77,38\% e a sotavento foi de $93,32 \%$. Os gradientes pluviométricos calculados apontam para acréscimo de chuva na vertente de barlavento da ordem de $0,83 \mathrm{~mm}$ por metro de altitude e decréscimo dos valores observados a sotavento da ordem de 0,37 mm de chuva por metro. Estas análises são importantes ao indicar a influência do relevo na relação chuva $x$ altitude.

Milanesi e Galvani (2011) encontraram correlações e gradientes pluviométricos superiores aos expostos neste trabalho. Deve-se destacar que, na área de estudo destes autores, o efeito orográfico nas chuvas é mais pronunciado, em função da maior altitude da formação rochosa e o movimento das brisas marinhas. Estas características da região de São Paulo geram o modelo clássico da chuva orográfica, a Autoconversão, conforme debatem Milanesi e Galvani (2011).

A partir dos dados observados, calculou-se a esta- 


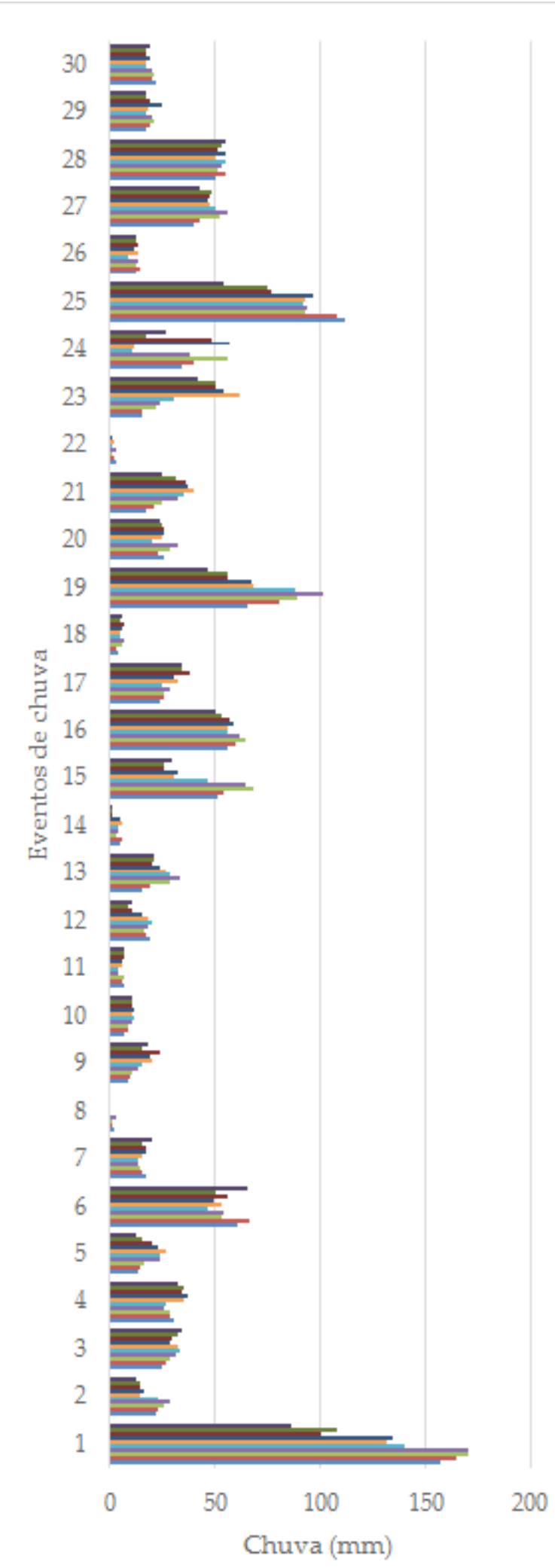

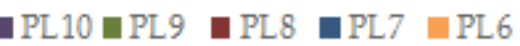

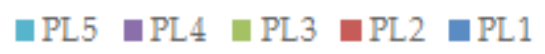

Figura 4. Chuva (mm) em cada posto pluviométrico.

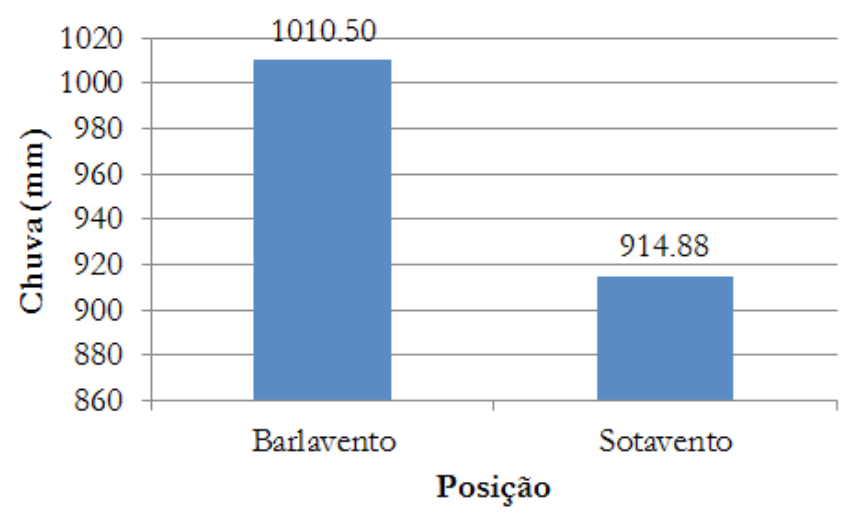

Figura 5. Chuva média (mm) a Barlavento (PL1 a PL4) e a Sotavento (PL5 a PL10)

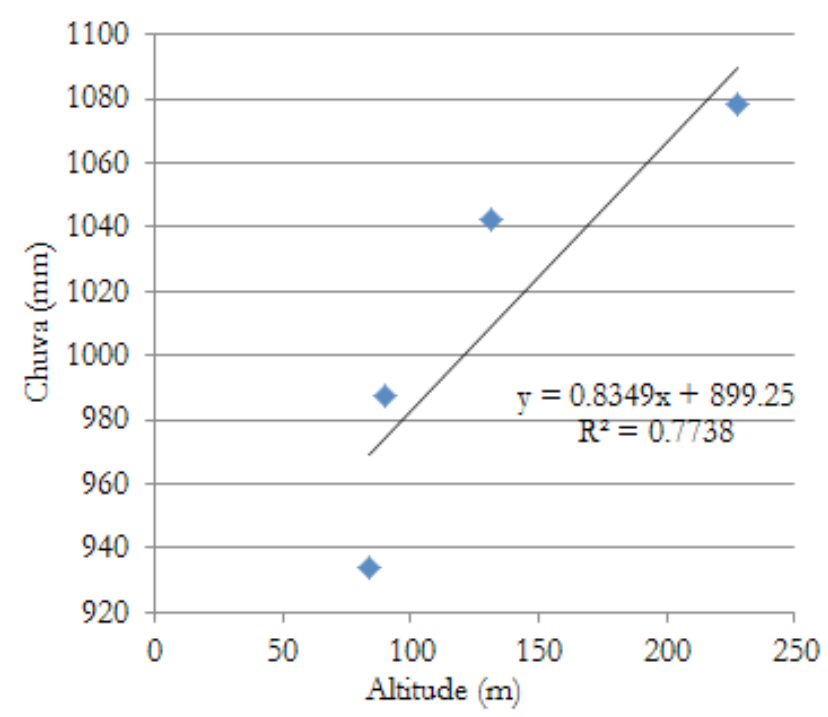

Figura 6. Correlação entre a chuva e a altitude nos pluviômetros a Barlavento (PL1 a PL4).

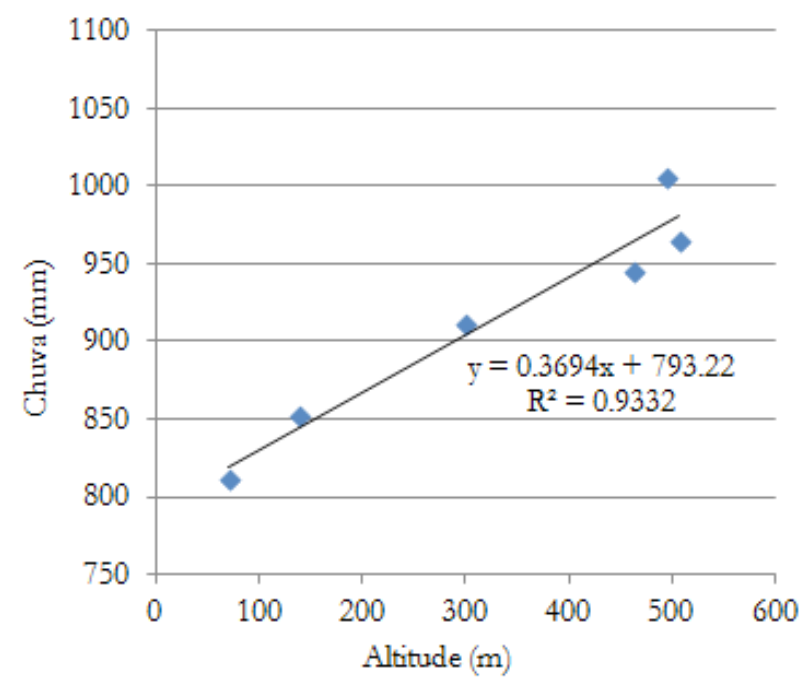

Figura 7. Correlação entre a chuva e a altitude nos pluviômetros a Sotavento (PL5 a PL10). 
tística do teste de hipóteses (t calculado), utilizando as Equações 1 e 2 . O valor encontrado foi de 1,92. Ao nível de significância de $5 \%$ o t tabelado é de 1,86. Assim, como o $t$ calculado foi superior ao $t$ tabelado, os dados sugerem a ocorrência de efeito orográfico nas chuvas para os eventos observados.

Contudo, analisando separadamente cada um dos eventos observados, observaram-se comportamentos diversos dos totais precipitados. Por exemplo, os eventos 15 e o 23 (Tabela 1), que apresentam totais precipitados semelhantes, respectivamente ocorridos em 20/09/2011 e 14/01/2012. A Figura 8 detalha os eventos. No evento de 20/09/2011, fica pronunciado um aumento da pluviosidade a barlavento e diminuição a sotavento. Já no evento de 14/01/2012, ocorre o contrário. A partir desta análise, surgiu a questão: o que causa esta variabilidade?

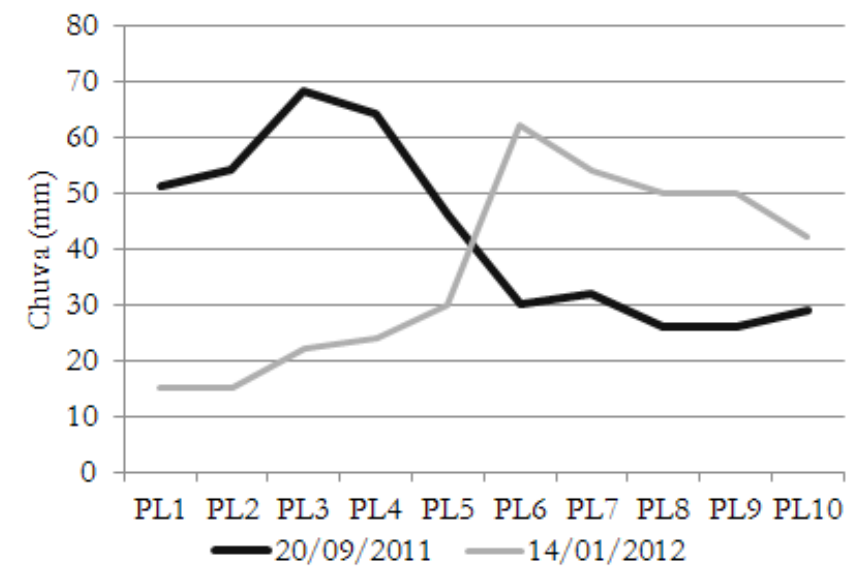

Figura 8. Eventos observados em 20/09/2011 e $14 / 01 / 2012$

Procurando responder esta questão foram analisadas imagens do satélite GOES disponíveis no banco de dados do INPE (DSA/CPTEC/INPE, 2013). As Figuras 9 e 10 apresentam as imagens sobre a América do Sul, respectivamente para os eventos observados em 20/09/2011 e 14/01/2012. Percebe-se que o evento de 2011 ocorreu devido ao movimento de uma massa de ar polar, enquanto que o evento de 2012 ocorreu devido ao avanço de uma massa de ar equatorial, oriunda do canal de umidade da Amazônia. Esta observação corrobora a descrição de Khan e Kim (1998) sobre os diferentes mecanismos climáticos que acontecem no Estado.

As invasões das massas de ar polares, no Estado do Rio Grande do Sul, ocorrem, geralmente, no outono e inverno e as invasões das massas de ar subtropicais ou equatoriais ocorrem na primavera e verão. Contudo, conforme relatam Khan e Kim (1998), podem acontecer diferentes interações entre estes mecanismos climáticos, alterando estas épocas. Os autores argumentam que a situação geográfica nesta região impõe à dinâmica atmosférica um complexo jogo entre massas de ar, e não o predomínio deste ou aquele sistema.

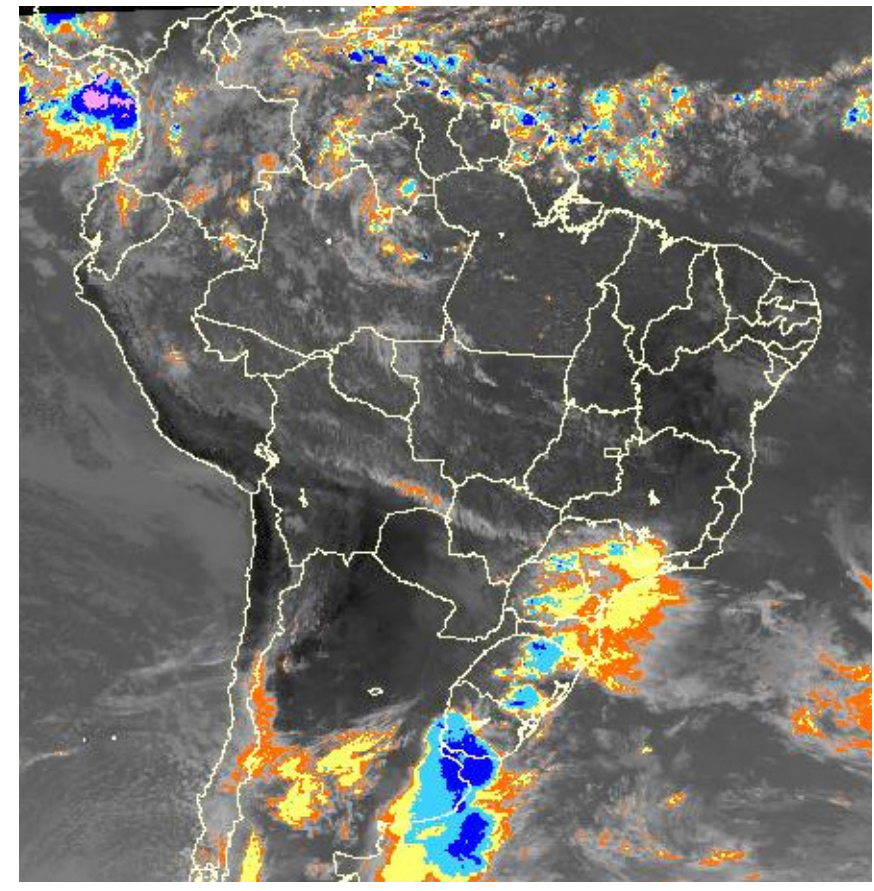

Figura 9. Imagem do Satélite GOES em 20/09/2011 (DAS/CPTEC/INPE, 2013).

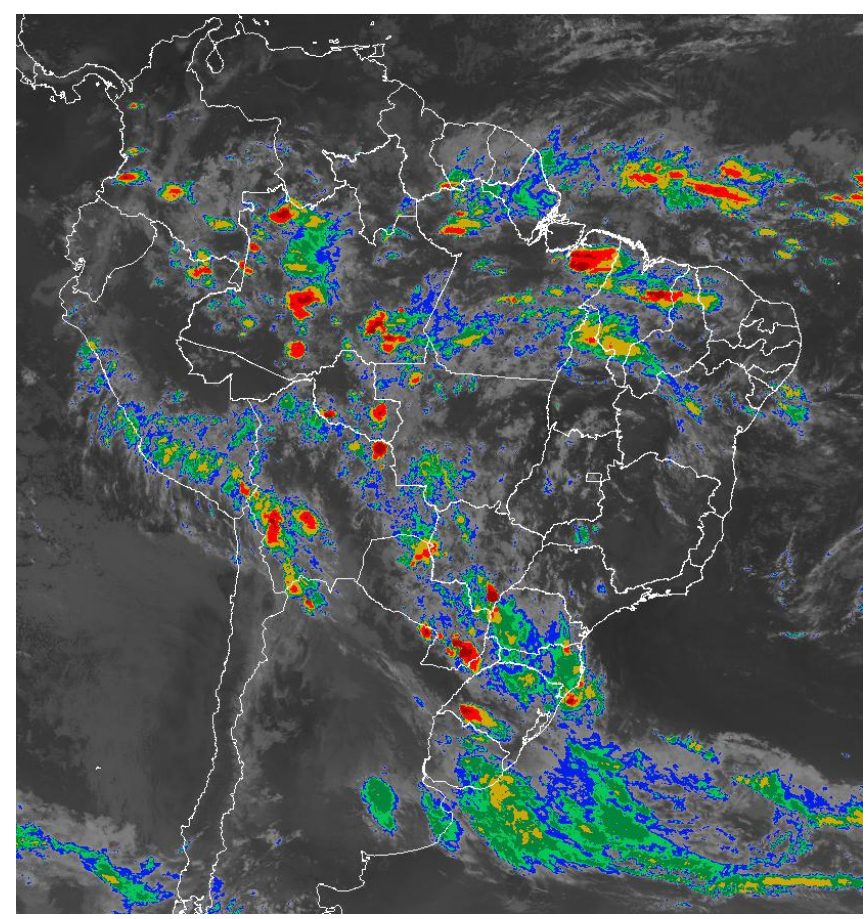

Figura 10. Imagem do Satélite GOES em 14/01/2012 (DAS/CPTEC/INPE, 2013).

A partir destas discussões, foi realizada outra análise referente aos totais médios sazonais de chuva observados. A Figura 11 apresenta os totais sazonais do ano hidrológico observado. A vertente de barlavento, em todas as estações, apresenta-se mais úmida que a vertente a 
sotavento. Entretanto, pode-se observar que a maior variação deu-se nos meses de maior pluviosidade, no outono e inverno. No outono, a diferença foi de $17 \%$, no inverno foi de $8,5 \%$, com $5 \%$ na primavera e, a menor diferença, no verão com $4,3 \%$.

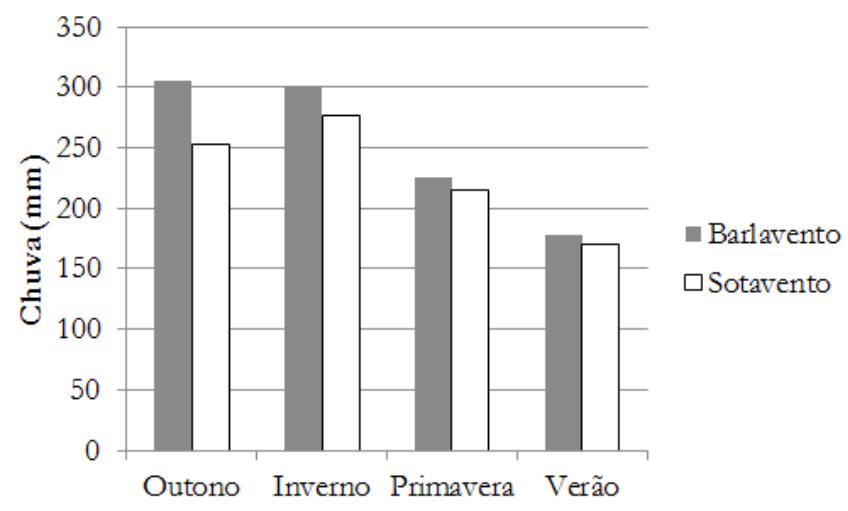

Figura 11. Totais médios sazonais de chuva (mm) por vertente e estação do ano.

Com estes resultados, pode-se admitir que quando o movimento da massa de ar é na direção sudoeste-nordeste ocorre maior pluviosidade a barlavento, devido ao choque da massa de ar polar com a formação montanhosa. Quanto o movimento da massa de ar é na direção noroeste-sudeste, invertendo as posições barlavento e sotavento, pode acontecer o contrário, conforme evento de janeiro de 2012, ou não haver variação significativa dos totais precipitados, conforme observado nos eventos ocorridos na primavera e verão (Figura 11).

Os eventos que ocorrem na região, nos meses de outono e inverno, são decorrentes de chuvas frontais, que são eventos de longa duração. Neste sentido, o efeito orográfico observado intensificou estas chuvas frontais. Pellegatti e Galavani (2010), Seluchi et al. (2011) e Liebmann et al. (2011) encontraram resultados semelhantes.

Pellegatti e Galavani (2010) e Seluchi et al. (2011) analisaram as chuvas ocorridas na Serra do Mar e verificaram que, durante eventos de curta duração, a variação dos totais de precipitação é significativamente inferior à variação espacial durante os eventos de longa duração. Durante os de curta duração, predominam sistemas convectivos, localizados e típicos de verão, ao passo que, durante eventos de longa duração, predominam sistemas frontais, sendo registrados totais de precipitação muito superiores nos postos localizados na vertente de barlavento da frente.

Assim, os dados do ano hidrológico 2011-2012 sugerem que o efeito orográfico, comprovado estatisticamente, tem sua ocorrência dependente da direção sudoeste-nordeste das massas de ar polares, nos meses de outono e inverno.

Esta dinâmica diferencia-se de outras regiões do país, por exemplo, no interior do Estado de São Paulo, entre o Vale do Rio Tietê e a Serra da Mantiqueira. No estudo de Cândido e Nunes (2008), foi observado que as maiores variações de precipitação, decorrentes do efeito orográfico, ocorreram nos meses de primavera e verão. Segundo os autores, nesta região a dinamização orográfica é particularmente favorecida quando da ocorrência de chuvas convectivas.

\section{Conclusões}

Observou-se a influência do relevo nas chuvas ocorridas em Silveira Martins, centro do Estado do Rio Grande do Sul. Porém, esta influência está condicionada à predominância do avanço das massas de ar polares (direção principal sudoeste-nordeste), em detrimento à invasão de massas de ar subtropicais (direção principal nordeste-sudeste).

No Estado do Rio Grande do Sul não existe um predomínio no movimento das massas de ar, ou seja, ocorre uma variação da direção do vento, o que condiciona a ocorrência do efeito orográfico na região estudada. Assim como a maioria das regiões do país, os dados climatológicos históricos, da região central do Rio Grande do Sul, são escassos, sendo necessário avançar na instalação de postos de monitoramento. Nesse aspecto, deve-se continuar o monitoramento da chuva orográfica na região.

O estudo da maior pluviosidade a barlavento pode contribuir para minimizar os impactos de eventos extremos de chuva na região, que resultam em prejuízos sócio-econômicos. A maioria destes eventos está associada às instabilidades severas do tempo, que causam inundações em pequenas bacias de encosta.

\section{Referências}

BRUNO, I. P. Balanço Hídrico e Avaliação da Chuva na Cultura do Cafeeiro. 2006. 53f. Dissertação (mestrado em Fitotecnia) - Universidade de São Paulo Escola Superior de Agricultura "Luiz de Queiroz". 2006.

CÂNDIDO, D., NUNES, L.. Influência da orografia na precipitação da área entre o Vale do Rio Tietê e a Serra da Mantiqueira. GEOUSP: espaço e tempo, América do Norte, 0, jun. 2011. Disponível em: http://citrus.uspnet.usp.br/geousp/ojs-2.2.4/ index.php/geousp/article/view/204/86. Acesso em: 10/09/2013.

\section{DSA/CPTEC/INPE (2013). Bando de Dados}

de Imagens. Divisão de Satélites e Sistemas Ambientais - Centro de Previsão de Tempo e Estudos Climáticos - Instituto Nacional de Pesquisas Espaciais. Disponível em http://satelite. cptec.inpe.br/acervo/goes_anteriores.jsp, acesso em 28/05/2013. 
IBGE - Instituto Brasileiro de Geografia e Estatística. Cidades: Silveira Martins. 2011. Disponível em: $<$ http://www.ibge.gov.br/cidadesat/topwindow. htm?1>. Acesso em: 25/09/2011.

KHAN, V.; KIM, I. A Análise de Agrupamento Pluviométrico nos Estados do Rio Grande do Sul e Santa Catarina. X Congresso Brasileiro de Meteorologia. Brasília, 1998.

LIEBMANN, B.; KILADIS, G.N., ALLURED, D., VERA, C.S., JONES, C., CARVALHO, L.M.V., BLADÉ, I., GONZÁLES, P.L.M. 2011: Mechanisms Associated with Large Daily Rainfall Events in Northeast Brazil. J. Climate, 24, 376-396. doi: http://dx.doi.org/10.1175/2010JCLI3457.1

MENDONÇA, F., DANNI-OLIVEIRA, I. M. Climatologia: noções básicas e climas do Brasil. São Paulo: Oficina dos Textos, 2007. 206 p.

MILANESI, M.A. e GALVANI, E. Efeito orográfico na Ilha de São Sebastião (Ilha Bela - SP). Revista Brasileira de Climatologia. ISSN: 2237-8642 (Eletrônica). N. 9 - Jul/Dez/2011.

PELLEGATTI, C.H.G. E GALVANI, E. Avaliação da precipitação na Serra do Mar-SP em eventos de diferentes intensidades e durações. GEOUSP Espaço e Tempo, São Paulo, № 27, pp. 147 - 158, 2010.

REICHARDT, K., ANGELOCCI L.R., BACCHI, O.O.S., PILOTTO, J.E. Daily Rainfall Variability At A Local Scale (1,000 Ha), In Piracicaba, SP, Brazil, And Its Implications On Soil Water Recharge. Departamento de Física e Meteorologia-ESALQ/ USP, 1995.

\section{SCP/DEPLAN. Atlas socieconômico do Rio Grande} do Sul: índice de mapas. 2004. Disponível em. $<$ http://www.scp.rs.gov.br/atlas/indice_mapas. asp?menu=331>. Acesso em 02/08/2011.

\section{SELUCHI, M.E.; CHAN CHOU, S.; GRAMANI,} $\mathrm{M}$. A case study of a winter heavy rainfall event over the Serra do Mar in Brazil. Geofís. Intl, México, v. 50, n. 1, marzo 2011. Disponível em $<$ http://www.scielo.org.mx/scielo.php?script=sci arttext\&pid=S0016-71692011000100005\&lng=es\&nr $\mathrm{m}=\mathrm{iso}>$. Acesso em 04/09/2013.

SPIEGEL, M.R., SCHILLER,J.J., SRINIVASAN, R.A. Teoria e problemas de probabilidade e estatística. Tradução de Sara Ianda Correa Carmona - 2 Ed. Porto Alegre: Brookman, 2004. 398p.
TUCCI, C.E.M. (Org). Hidrologia: Ciência e Aplicação. $2^{\circ}$ Ed. Porto Alegre: ED. UFRGS: ABRH, 2001. 943p. 